\title{
Evaluation of Sexual Function in Breast feeding Women
}

I.Y.Abdallah, D.M.EL-Habak, E.A.Abd Elaziz

Dermatology, Venerology\&AndrologyDept., Faculty of Medicine, Benha Univ., Benha, Egypt

E-Mail:elhamabdo454@gmail.com

\begin{abstract}
Breastfeeding is firmly supported by pediatric and obstetric associations. Its constructive outcome on maternal wellbeing is undebatable, yet numerous scientists saw breastfeeding as a significant hazard factor for baby blues female sexual brokenness. Point: Evaluate the effect of breastfeeding on female sexual capacities. a self-report survey structured by the creators guided by the female sexual capacity record (Rosen et al, 2000). The point of the investigation and the subtleties of the poll were disclosed to the ladies before taking their educated assent. Members were 300 ladies enrolled from those going to the Maternity and Childhood Centers and Birketelsabaa General Hospital. Reduction every sexual capacity in breastfeeding women.The present examination discoveries demonstrate that sexual capacities as want, grease and climax decline in breastfeeding ladies. Likewise, dyspareunia is a typical protest among lactating moms. A few components influence female sexual capacity in breastfeeding ladies as kind of breastfeeding, training and word related status.
\end{abstract}

Keywords: Female sexual function, Breastfeeding,Types of breastfeeding.

\section{Introduction}

Sexuality speaks to a significant part of human personality and considerably adds to personal satisfaction for the two ladies and men [1].

Female sexual capacity incorporates moxie, excitement, torment, and climax; continuing unsettling influences in any of these territories, or rather issue identifying with sexual want and sexual fulfillment, are alluded to as female sexual brokenness (FSD) [2].

There are a few bio-psychosocial factors expected to influence sexual practices. Pregnancy and baby blues period (a half year after conveyance) effectsly affect ladies' and their spouses' sexual coexistence [3].

Then again the greater part of the baby blues ladies pick breastfeeding and it will meddle with the couples' sex. The physical, hormonal, and mental modifications in the body from origination to baby blues and breastfeeding make an incredible potential for change in a lady's sexuality. It has been demonstrated that sexual brokenness happens for first labors [4].

As to relationship among breastfeeding and peripartum sexual working, the current writing is mostly clashing. While a few examinations recommended a beneficial outcome of breastfeeding on baby blues sexuality because of expanded bosom affectability and oxytocin levels [5].

Others saw breastfeeding as a significant hazard factor for baby blues sexual brokenness; with regards to hormonal concealment, it could be connected to sex not being continued, dyspareunia, oil and excitement issues just as diminished sexual want [6].

Low estrogen levels can cause diminished vaginal oil and decay of the vaginal epithelium, which, thus, make physical excitement troublesome and intercourse difficult [7].

Dyspareunia, or agony with intercourse, is a typical protest of breastfeeding ladies [8].

\section{Material and methods}

The current investigation is a cross sectional examination. The members of this investigation were breastfeeding hitched ladies. Work began in the wake of taking the endorsement of the Ethical Committee and Dermatology \&Andrology division in Benha University. The investigation apparatus was a selfreport poll structured by the creators guided by the female sexual capacity file (Rosen et al, 2000) with expansion of certain inquiries that suit the current examination.

The point of the investigation and the subtleties of the poll were disclosed to the ladies before taking their educated assent.

Members of the investigation were 300 ladies enrolled from those going to the Maternity and Childhood Centers and Birketelsabaa General Hospital in the period between October 2019 and April 2020.

\subsection{Statistical analysis}

Information were taken care of to the PC and broke down utilizing IBM SPSS programming bundle variant 20.0. (Armonk, NY: IBM Corp)Qualitative information were depicted utilizing number and percent. Noteworthiness of the got outcomes was decided at the $5 \%$ level.

\section{Results and discussion}

Table (1)Data of breastfeeding $(n=300)$.

\begin{tabular}{ccc}
\hline & $\mathbf{n}$ & \% \\
\hline Breastfeeding started & & \\
Less than 6 months & 146 & 48.7 \\
6 To 12months & 75 & 25.0 \\
More than one year & 79 & 26.3 \\
Type of lactation & &
\end{tabular}


Table (1) Continue

Exclusive breastfeeding $\quad 193 \quad 64.3$

Breast \& bottle feeding

107

Table (2) Sexual activity among participants $(n=300)$.

\begin{tabular}{|c|c|c|}
\hline & $\mathbf{n}$ & $\%$ \\
\hline \multicolumn{3}{|l|}{ Coital restart after delivery } \\
\hline 1 month & 108 & 36.0 \\
\hline 2 months & 163 & 54.3 \\
\hline 3 months & 19 & 6.3 \\
\hline 4 months or more & 10 & 3.3 \\
\hline \multicolumn{3}{|l|}{ Coital frequency } \\
\hline Daily & 3 & 1.0 \\
\hline 2-3 times per week & 123 & 41.0 \\
\hline Once a week & 151 & 50.3 \\
\hline Once a month & 16 & 5.3 \\
\hline Less than that & 7 & 2.3 \\
\hline \multicolumn{3}{|l|}{ Unprovoked desire } \\
\hline Many times per day & 3 & 1.0 \\
\hline Once per day & 21 & 7.0 \\
\hline Weekly & 115 & 38.3 \\
\hline Monthly & 71 & 23.7 \\
\hline Almost never & 90 & 30.0 \\
\hline \multicolumn{3}{|l|}{ Desire level } \\
\hline Very high & 5 & 1.7 \\
\hline High & 19 & 6.3 \\
\hline Moderate & 112 & 37.3 \\
\hline Low & 164 & 54.7 \\
\hline \multicolumn{3}{|l|}{ Lubrication rate } \\
\hline Almost every time & 55 & 18.3 \\
\hline More than half the times of sexual encounters & 41 & 13.7 \\
\hline About half the times of sexual encounters & 53 & 17.7 \\
\hline Less than half the times of sexual encounters & 104 & 34.7 \\
\hline Almost never & 47 & 15.7 \\
\hline \multicolumn{3}{|l|}{ Lubrication difficulty } \\
\hline Not difficult & 51 & 17.0 \\
\hline Slightly difficult & 40 & 13.3 \\
\hline Very difficult & 162 & 54.0 \\
\hline Never & 47 & 15.7 \\
\hline \multicolumn{3}{|l|}{ Orgasm rate } \\
\hline Every time & 30 & 10.0 \\
\hline More than half the times of sexual encounters & 37 & 12.3 \\
\hline About half the times of sexual encounters & 72 & 24.0 \\
\hline Less than half the times of sexual encounters & 103 & 34.3 \\
\hline Never & 58 & 19.3 \\
\hline \multicolumn{3}{|l|}{ Dyspareunia } \\
\hline Every time & 77 & 25.7 \\
\hline More than half the times of sexual encounters & 65 & 21.7 \\
\hline About half times of sexual encounters & 58 & 19.3 \\
\hline Less than half times of sexual encounters & 70 & 23.3 \\
\hline Almost never & 30 & 10.0 \\
\hline \multicolumn{3}{|l|}{ Sexual satisfaction } \\
\hline Very satisfied & 89 & 29.7 \\
\hline Moderately satisfied & 102 & 34.0 \\
\hline Dissatisfied & 109 & 36.3 \\
\hline
\end{tabular}


Table (3)Relation of breastfeeding to some female sexual aspects $(n=300)$.

\begin{tabular}{lcc}
\hline & $\mathbf{n}$ & $\mathbf{\%}$ \\
\hline Sexual changes with breastfeeding to worse & & \\
Yes & 229 & 76.3 \\
No & 71 & 23.7 \\
Husband complains about decrease in desire & & \\
Yes & 184 & 61.3 \\
No & 116 & 38.7 \\
Response to breast stimulation & & \\
Increased response & 196 & 65.3 \\
Decreased response & 50 & 16.7 \\
No change & 54 & 18.0 \\
Orgasm by breast stimulation only & & \\
Yes, all times & 36 & 12.0 \\
Sometimes & 57 & 19.0 \\
Never & 207 & 69.0 \\
\hline
\end{tabular}

\section{Discussion}

Breastfeeding is unequivocally energized by pediatric and obstetric associations [9]. Its constructive outcome on maternal wellbeing is undebatable, however numerous analysts saw breastfeeding as a significant hazard factor for baby blues female sexual brokenness [6].

Our investigation revealed that the greater part of members began breastfeeding from under a half year $(48.7 \%)$ and most of them $(64.3 \%)$ rehearsed select breastfeeding. This outcome concurs with The World Health Organization (WHO) suggestions that suggest restrictive breastfeeding for a half year after conveyance [10].

The current examination shows the impact of breastfeeding on the various parts of female sexuality. The greater part of ladies restarted sex following two months from conveyance $(54.3 \%)$. This outcome concurs with the examination directed by [4] that demonstrated a solid connection among breastfeeding and resumption of baby blues sex, to such an extent that breastfeeding moms had a later beginning of baby blues sexual action contrasted and bottle taking care of ladies.

Our investigation discoveries indicated an unwanted degree of sexuality. The vast majority of members have decline in coital recurrence, ridiculous want, want level, oil, climax rate, sexual fulfillment and the majority of them gained dyspareunia. The investigation shows that $76.3 \%$ of ladies felt that their sexual action changed to more terrible during lactation and $61.3 \%$ of members got objections from their spouses about their low want. This outcome concurs with [11] who detailed female sexual capacities including want, oil and fulfillment were essentially diminished during lactation because of hormonal, physical and mental expressions of love. A few specialists as [12] accept that breastfeeding invigorates sexuality and these moms experience the most significant level of moxie. Breastfeeding ladies accepted that expanded drive may be because of bigger bosom size, direct physical incitement and expanded affectability.

Then again, in an exploration performed by [13] $75 \%$ of the ladies expressed that lactation had little effect on their sexual life. Thus, in an investigation by [5] detailed that $74.6 \%$ of taking part primiparous ladies said that they had no issue in sex during breastfeeding, albeit $45.3 \%$ of them expressed, in the wake of weaning, that it had meddled with their sexual coexistence.

Our investigation detailed that climax by bosom incitement just never happened in $69 \%$, now and again felt in $19 \%$ and felt all occasions in $12 \%$ of ladies. This outcome concurs with [14] who found that extra genital zones that gave the most elevated energizing impact when animated were the bosoms and areolas, trailed by the lips, the neck and the scruff of the neck, the ears, and the hindquarters and furthermore detailed that in spite of the fact that climax is naturally a reaction to genital incitement, different kinds of tangible incitement likewise can create climax.

Our current examination shows that the vast majority of members saw that their self-perception changed to better during lactation, were exceptionally fulfilled about these body changes, felt that they were the equivalent explicitly alluring as before pregnancy and not presented to spouse boisterous attack about their body shape. This outcome concurs with [15] who detailed that with bosom taking care of there will be a progressively fast weight reduction and come back to pregestational conditions, with a normal month to month decrease of $450 \mathrm{~g}$ in the maternal weight, since the discharged oxytocin likewise applies its lipolytic and anorexigenic impacts.

The vast majority of members had dull earthy colored areola. Researchers feel that the areolas may obscure to help an infant hook on to its mom's bosoms. Yet, hormonal vacillations that empower milk creation 
are additionally liable to cause some adjustment in the shade of the areolas. Babies have poor vision, and darker areolas might be a developmental method of helping an infant discover their food source. The areolas will come back to their past shading over the long haul subsequent to breastfeeding has finished [16].

Our current examination shows that ladies who rehearsed elite breastfeeding had a lot of lower want, lower climax, lower oil, more oil trouble and more dyspareunia than ladies who rehearsed both bosom and container taking care of. This outcome concurs with [3] who uncovered that moms rehearsing selective breastfeeding can have more issues with vaginal oil and sexual incitement than others.

In our examination there was a high measurably critical connection between's various degrees of training and unwarranted want, climax and oil ( $\mathrm{p} \leq$ 0.05). College degree holders have better sexual capacities including want, grease and climax than the lower training. There was no factually critical impact on dyspareunia $(p>0.05)$.This outcome concurs with [17] who demonstrated that ladies with advanced education would confront sexual brokenness less regularly.

The current examination shows that working ladies had huge lower want, poor grease and more dyspareunia than housewives. This outcome concurs with [18] who found that female sexual dysfunctions were exceptionally common among working ladies.

\section{Conclusion}

The present study findings indicate that sexual functions as desire, lubrication and orgasm decrease in breastfeeding women. Also, dyspareunia is a common complaint among lactating mothers. Several factors affect female sexual function in breastfeeding women as type of breastfeeding, education and occupational status.

\section{References}

[1] L. Bossini, V. Fortini, I. Casolaro, Sexual dysfunctions, psychiatric diseases and quality of life: A review. Psychiatr Pol,Vol.48(4), PP.715$726,2014$.

[2] P. Abedi, M. Jorfi, P. Afshari,How does healthpromoting lifestyle relate to sexual function among women of reproductive age in Iran?. Health PromotGlob,Vol. 25(3), PP.15-21, 2017.

[3] A.K. LaMarre ,L.Q. Paterson ,Breastfeeding and postpartum maternal sexual functioning: A review. Can J Hum Sex, Vol.12(3/4), PP.151,2003.

[4] M. Rowland, L. Foxcroft, W.M. Hopman,Breastfeeding and sexuality immediately
postpartum.CanFam

Physician,Vol.51(10), PP.1366-1367,2004.

[5] M.D. Avery, L. Duckett, C.R. Frantzich, The experience of sexuality during breastfeeding among primiparouswomen.J Midwifery Women's Health ,Vol.45(3), PP.227-237.

[6] N. Rezaei, A. Azadi, K. Sayehmiri,Postpartum sexual functioning and its predicting factors among Iranian women. Malays J Med Sci,Vol.24(1), PP.94-103,2017.

[7] L.B. Signorello, B.L. Harlow, A.K. Chekos,Postpartum sexual functioning and its relationship to perineal trauma: a retrospective cohort study of primiparous women. AmJObstetGynecol,Vol. 184(5), PP.8818,2001 .

[8] A. Connolly, J. Thorp,L. Pahel,Effects of pregnancy and childbirth on postpartum sexual function: alongitudinal prospective study. IntUrogynecolJ Pelvic Floor Dysfunct,Vol.16(4), PP.263, 2005.

[9] [9] M.S. Kramer,R. Kakuma ,The optimal duration of exclusive breastfeeding.Cochrane Database Syst Rev, Vol.8, pp.63-77, 2013.

[10] W.H.O ,Infant and young child feeding Fact, vol. 25(5), pp.213-9, 2014.

[11]E. McDonald, H. Woolhouse ,S.J. Brown ,Consu ltation about Sexual Health Issues in the Year after Childbirth: A Cohort Study. Birth,Vol.42, PP.354-61, 2015.

[12]M. AliakbariDehkordi,Relationship between women sexual function and marital adjustment. J Behav Sci,Vol.4(3), PP.11-2,2010.

[13] J.A. Kenny,Sexuality of pregnant and breastfeeding women. Arch Sex Behav,Vol.2(3), PP.215-29,1973.

[14]I.Younis, F. El-Esawy,R. Abdel-Mohsen,Is female orgasm anearth-moving experience: an Egyptian experience.HumAndrol, Vol.5, PP.37-44,2015.

[15] T.S. Toma,M.F. Rea , Benefits of breastfeeding for maternal and child health: an essay on the scientific evidence. J Cad SaudePublica,Vol.24, PP.235-246,2008.

[16]Fletcher J ,What causes dark nipples?Medical News Today,Vol. 25(5), PP.213-9,2018.

[17]B.A. Fajewonyomi, E.O. Orji ,A.O. AdeyemoSexual dysfunction among female patients of reproductive age in a hospital setting in Nigeri. J Health PopulNutr, Vol. 25(1), PP. 101$106,2007$.

[18] K. Stamatiou, M. Margarit, E.I. Eftichia, Female sexual dysfunction(FSD) in women health care workers. Mater Sociomed, Vol.28(3), PP. 178-182, 2016. 